wWw.jmscr.igmpublication.org

Impact Factor 5.244

Index Copernicus Value: 5.88

ISSN (e)-2347-176x ISSN (p) 2455-0450

crossref DOI:_http://dx.doi.org/10.18535/jmscr/v4i3.12

Journal Of Medical Science And Clinical Research

\title{
A 3 Year Study of Maternal Mortality at Government Medical College, Kota
}

Authors

\section{Dr Vinita Bansal ${ }^{1}$, Dr Pooja Saini ${ }^{2}$}

${ }^{1}$ Medical Officer Cum Clinical Tutor, MS Obs and Gynae

${ }^{2} 2^{\text {nd }}$ Year Resident Obs and Gynae

Department of Obstetrics \& Gynecology, Government Medical College, Kota

\begin{abstract}
Background: Maternal mortality continues to be a major public health problem in the developing world. Maternal mortality is a vital index of the effectiveness of obstetric services prevailing in a country. The present study was conducted at GMC,Kota which is a major referral centre with an average of 800-1000 deliveries per month.
\end{abstract}

Methods: Data on the maternal deaths at GMC, Kota from january 2013 to december 2015 during pregnancy and within 42 days of delivery of any cause, irrespective of the duration and site of pregnancy were collected. Results: The maternal mortality ratio for the study period was per 1,00,000 live births. Among the 96 maternal deaths, 16 deaths (16.66\%) occurred in primigravida, 20 deaths $(20.83 \%)$ had occurred in primipara, 9 deaths $(9.37 \%)$ in gravida 2,13 deaths $(13.54 \%)$ in para 2,13 death $(13.54 \%)$ in gravida 3,16 deaths $(16.66 \%)$ in para 3 and 9 deaths (9.37\%) had occurred in para 4 and above. During the study period, 11 deaths (11.45\%) occurred within 1 hour of admission, 28 deaths (29.16\%) within 1-6 hours of admission, 12 deaths (12.5\%) between 7-12 hours of admission, 19deaths (19.79\%) between 13-24 hours, 12 deaths (12.54\%) between 1-2 days and 14 deaths(14.58\%) occurred after 2 days of admission. Maternal deaths had occurred mostly in delivered women (79.96\%) compared to undelivered women (20.83\%). During the study period, among the 96 maternal deaths, 78 deaths (81.25\%) occurred due to direct obstetric causes and 18 deaths (18.75\%) due to indirect causes. Among the direct obstetric causes, haemorrhage (33.33\%) and hypertensive disorders of pregnancy (35.41\%) were the leading causes. Pulmonary embolism (6.25\%), rupture uterus (3.12\%), septic abortion (2.08\%) and acute inversion of uterus (1.04\%) were the other direct causes of maternal deaths. Among the indirect obstetric causes, 13 deaths (13.54\%) occurred due to anaemia which was the leading cause. One death (1.04\%) occurred due to swine flu and 2 death $(2.08 \%)$ due to hepatic failure,1 death $(1.04 \%)$ due to acute myeloid leukemia,1 death(1.04\%) due to renal failure.

Conclusions: Reviewing the maternal deaths that occurred in our hospital, there is an urgent need to address the issue of obstetric haemorrhages and early intervention in PIH. Much needs to be done for maternal health care in rural areas as most of the deaths reported from urban institutions are referrals from peripheral centres. Rapid transport facilities should be made available to all remote rural areas with easy accessibility. It is necessary even in urban areas to channel the working of emergency obstetric care. This prevents early intervention and adequate emergency obstetric care. The essential obstetric care for all and early detection of complications and management of emergency obstetric care services need to be seriously looked into. Most maternal deaths are preventable by health education of masses, adequate health care in the community and transport facilities. 


\section{INTRODUCTION}

Maternal mortality continues to be one of the major public health problems especially in our country. Maternal mortality is a vital index of the effectiveness of obstetric services prevailing in a country. Maternal mortality is one area in Indian obstetrics where a strong concern and consensus is seen. Preeclampsia, postpartum hemorrhage and sepsis are the most important direct causes of maternal death. ${ }^{1,2}$ Anemia and jaundice are the two important indirect causes. ${ }^{1,2}$ The causes of maternal death in developing and developed countries are almost the same but there is a massive difference in women's chance of surviving the complications.

The important delays are in:

- Seeking help

- Reaching health care facility

- Diagnosis and substandard treatment and

- Arranging blood components due to lack of blood bank or lack of sufficient stock of blood products.

\section{METHODS}

\section{Source of data}

This is a clinical study of maternal deaths that occurred at GMC, Kota, from january 2013 to december 2015.

\section{Method of collection of data}

Data on the maternal deaths that occurred at GMC, Kota during pregnancy and within 42 days of delivery of any cause, irrespective of the duration and site of pregnancy were collected. The deaths were classified according to WHO classification as:

\section{Direct obstetric causes}

2. Indirect obstetric causes

3. Non-related causes

During the present study, total births include livebirths and stillbirths. Deaths due to abortions were also included, since it is one of the important causes of maternal deaths.

In the critical study of maternal mortality with regard to age, marital status, age at marriage, booked vs. unbooked, geographical location, educational status, socio-economic status, time interval since admission, mode of delivery, causes of death and various other factors have been considered.

\section{Inclusion criteria}

- All maternal deaths occurring during pregnancy and within 42 days of delivery

- Ectopic pregnancies

- Septic abortions

- Molar pregnancies

\section{Exclusion criteria}

- All maternal deaths occurring after 42 days of termination of pregnancy

- Accidents

\section{RESULTS}

It is noted that out of 96 maternal deaths during the study period, 46 deaths $(47.91 \%)$ have occurred in the age group of 21-25 years. 12 deaths $(12.5 \%)$ have occurred in the age group $<20$ years of age. 27 deaths (28.12\%) have occurred in the age group of 26-30 years, 11 death $(11.45 \%)$ have occurred in the age group of $>30$ years. (Table 1 ).

Table 1 MMR in relation to age of the patients.

\begin{tabular}{|c|l|l|}
\hline Age (years) & $\begin{array}{l}\text { Number } \\
\text { patients }\end{array}$ & of \\
\hline$<20$ & 12 & 12.5 \\
\hline $21-25$ & 46 & 47.91 \\
\hline $26-30$ & 27 & 28.2 \\
\hline$>30$ & 11 & 11.45 \\
\hline Total & 96 & 100 \\
\hline
\end{tabular}

During the study period, out of the total 96 cases, 78 cases $(81.25 \%)$ were unhooked and 18 cases $(18.75 \%)$ were booked cases. (Table 2). 
Table 2: MMR in relation to booked vs. unbooked.

\begin{tabular}{|lcc|} 
Booked/Unbooked & Number of & \\
& patients & Percentage \\
\hline Booked & 18 & 18.75 \\
\hline Unbooked & 78 & 81.25 \\
\hline Total & 96 & 100 \\
\hline
\end{tabular}

The rural population is at greater risk with regard to maternal death. During the study period, about 80 deaths ( $83.33 \%$ ) have occurred in rural population compared to 16 deaths (16.66\%) which have occurred in urban population. (Table 3 ).

Table 3: MMR in relation to geographical location.

\begin{tabular}{|cc|c|} 
Geographical & Number of & \\
& & \\
location & patients & \\
\hline Rural & 80 & 83.33 \\
\hline Urban & 16 & 16.66 \\
\hline Total & 96 & 100 \\
\hline
\end{tabular}

It was observed from the present study that majority of maternal deaths occurred in low and middle socio economic group. (Table 4).

Table 4: MMR in relation to socioeconomic status

\begin{tabular}{|c|c|c|}
\hline $\begin{array}{l}\text { Socioeconomic } \\
\text { status }\end{array}$ & $\begin{array}{l}\text { Number of } \\
\text { patients }\end{array}$ & Percentage \\
\hline Poor & 58 & 60.41 \\
\hline Average & 24 & 25 \\
\hline Good & 14 & 14.58 \\
\hline Total & 96 & 100 \\
\hline
\end{tabular}

It was noticed during the study period; about 46 patients $(47.91 \%)$ were illiterates. About 36 patients $(37.5 \%)$ had primary education. About 12 patients $(12.5 \%)$ had secondary schooling. Only 2 patient $(2.5 \%)$ was a graduate. Hence educational status is significantly associated with MMR (Table 5).
Table 5: MMR in relation to educational status.

\begin{tabular}{|c|c|c|}
\hline $\begin{array}{l}\text { Educational } \\
\text { status }\end{array}$ & $\begin{array}{l}\text { Number of } \\
\text { patients }\end{array}$ & Percentage \\
\hline Illiterate & 46 & 47.91 \\
\hline Primary & 36 & 37.5 \\
\hline Secondary & 12 & 12.5 \\
\hline Degree & 2 & 2.5 \\
\hline Total & 96 & 100 \\
\hline
\end{tabular}

It was observed that during the study period maternal deaths had occurred mainly in married women. No deaths had occurred in unmarried or widow, probably due to under reporting of the real picture. The average age at marriage was 18.40 years (13-27 years). During the study period, 31 deaths $(77.5 \%)$ have occurred in women who are married below 19 years of age. 7 deaths $(17.5 \%)$ have occurred in women who have married between 20 and 24 years of age. 2 deaths $(5 \%)$ have occurred in women who married after 25 years of age. Age at marriage is significantly associated with MMR and is statistically significant (Table 6).

Table 6: MMR in relation to age at marriage

\begin{tabular}{|c|cc|}
\hline Age (years) & $\begin{array}{c}\text { Number of } \\
\text { patients }\end{array}$ & Percentage \\
\hline Upto 19 & 74 & $77 . .08$ \\
\hline $20-24$ & 17 & 17.70 \\
\hline 25 and above & 5 & 5.2 \\
\hline Total & 96 & 100 \\
\hline
\end{tabular}

It was noted that out of 96 deaths during the study period, 16 deaths $(16.66 \%)$ have occurred in primigravidae, 20 deaths $(20.83 \%)$ have occurred in primipara, 9 deaths $(9.37 \%)$ have occurred in gravida 2 and, 13deaths (13.54\%) have occurred in para 2, 16 deaths $(16.66 \%)$ have occurred in para 3 and 9 deaths $(9.3 \%)$ have occurred in para 4 and above and it was not statistically significant (Figure 1). 


\begin{tabular}{|lcc|}
$\begin{array}{l}\text { Socioeconomic } \\
\text { status }\end{array}$ & $\begin{array}{c}\text { Number of } \\
\text { patients }\end{array}$ & Percentage \\
\hline Primigravida & 16 & 16.66 \\
\hline Primipara & 20 & 20.83 \\
\hline Gravida 2 & 9 & 9.3 \\
\hline & & \\
& & \\
Para 2 & 13 & 13.54 \\
\hline Gravida 3 & 13 & 13.54 \\
\hline Para 3 & 16 & 16.66 \\
\hline$\geq$ Para 4 & 9 & 9.3 \\
\hline Good & 96 & 100 \\
\hline
\end{tabular}

It was observed that in the present study out of 96 deaths, 11 deaths $(11.45 \%)$ occurred within 1 hour, 28 deaths $(29.16 \%)$ had occurred within 16 hours of admission, 12 deaths $(12.5 \%)$ had occurred between 7-12 hours, 19 deaths (19.79\%) had occurred between 13-24 hours, 12 deaths (12.5\%) had occurred between 25-48 hours of admission and 14 deaths $(14.58 \%)$ had occurred after 48 hours of admission and it was not statistically significant (Table 7).

Table 7: MMR in relation to admission-death interval

\begin{tabular}{|ccc|}
\hline $\begin{array}{c}\text { Interval } \\
\text { (hours) }\end{array}$ & $\begin{array}{l}\text { Number of } \\
\text { patients }\end{array}$ & Percentage \\
\hline$<1$ & 11 & 11.45 \\
\hline $1-6$ & 28 & 29.16 \\
\hline $7-12$ & 12 & 12.5 \\
\hline $13-24$ & 19 & 19.79 \\
\hline $25-48$ & 12 & 12.5 \\
\hline$>48$ & 14 & 14.58 \\
\hline & 96 & 100 \\
\hline
\end{tabular}

During the present study, about 76 deaths (79.16\%) had occurred in delivered patients and 20 deaths $(20.83 \%)$ had occurred in undelivered.

Out of 76 delivered cases during the study period, 58 patients $(76.3 \%)$ had vaginal delivery. 14 women (18.42\%) underwent emergency LSCS, 1 patient (1.31\%) had molar pregnancy for which suction evacuation was done. 1 patient $(1.31 \%)$ had ventouse assisted delivery. 2 patient (2.62\%) had abortion . (Table 8).
It was noticed from the present study, that the direct obstetric causes were responsible for 78 deaths $(81.25 \%)$. The indirect obstetric causes were responsible for 18 deaths $(18.75 \%)$

Table 8: MMR in relation to mode of delivery

\begin{tabular}{llc|}
$\begin{array}{l}\text { Mode of delivery } \\
\text { Vaginal }\end{array}$ & $\begin{array}{c}\text { Number of } \\
\text { patients }\end{array}$ & $\begin{array}{c}\text { Percenta } \\
\text { ge }\end{array}$ \\
\hline LSCS & 58 & 76.31 \\
\hline $\begin{array}{l}\text { Suction } \\
\text { evacuation }\end{array}$ & 14 & 18.42 \\
\hline $\begin{array}{l}\text { Ventouse } \\
\text { assisted }\end{array}$ & 1 & 1.31 \\
\hline $\begin{array}{l}\text { Abortion } \\
\text { Total }\end{array}$ & 1 & 1.31 \\
\hline
\end{tabular}

It was observed that 78 deaths $(81.25 \%)$ occurred due to direct obstetric causes. The important direct causes were haemorrhage contributing to 32 deaths $(33.33 \%)$, out of which 4 deaths were due to antepartum haemorrhage, 28 deaths due to postpartum haemorrhage Hypertensive disorders of pregnancy contribute for 34 deaths (35.41\%). pregnancy contribute for 34 deaths $(35.41 \%)$. and 2 death $(2.08 \%)$ was due to septic abortion. Pulmonary embolism was the cause of death in 6 cases $(6.25 \%) .1$ death $(1.04 \%)$ occurred due to acute inversion of the uterus. Among the indirect obstetric causes, anaemia was the leading cause contributing to about 13 maternal deaths. (13.54\%).2 death (2.08\%) occurred due to hepatic failure, 1 death(1.04)due to AML,1death(1.04) due to swine flu. (Figure 2). 


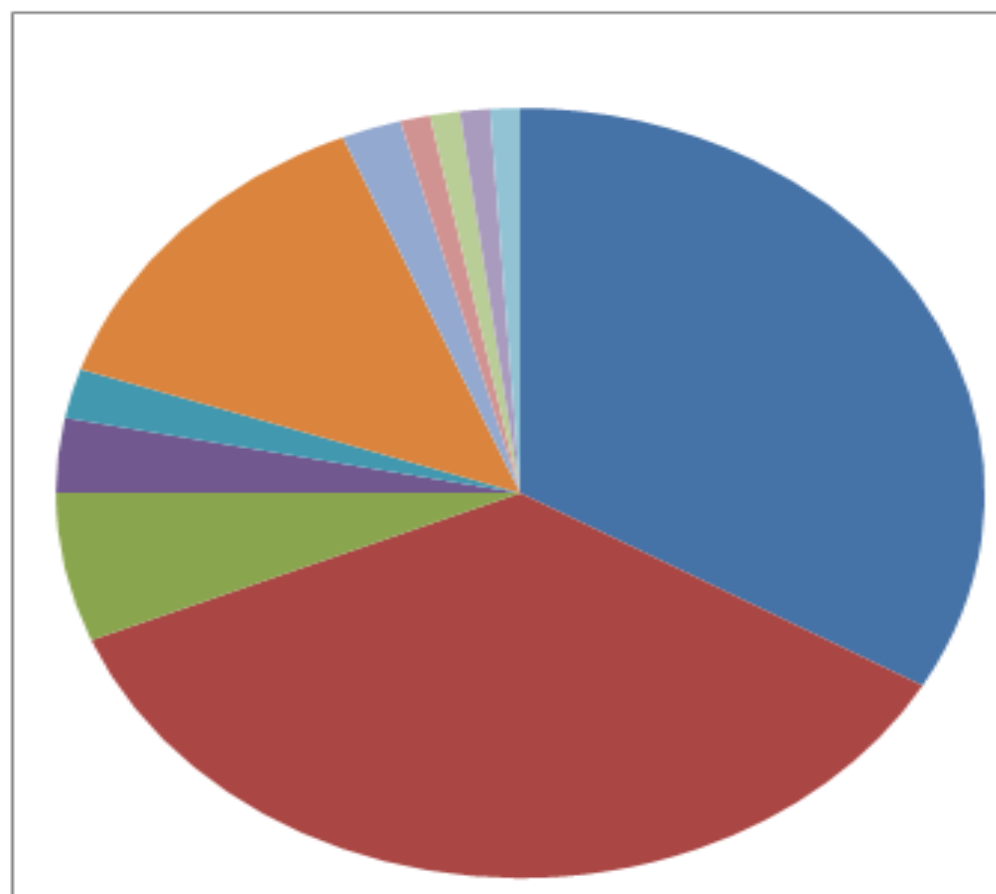

naemorrhage - $33.00 \%$

- Pre eclampsia \& Eclampsia $35.41 \%$

Pulmonary embolism - $6.25 \%$

Rupture uterus - $3.12 \%$

Septic abortion $-2.08 \%$

anaemia - $13.54 \%$

Hepatic diseases - $2.08 \%$

- Acute inversion of uterus $1.04 \%$

aML $-1.04 \%$

- Swine Flu - 1-04\%

- Renal Failure - $1.04 \%$

\section{DISCUSSION}

During this study period from January 2013 to December 2015, 96 maternal deaths have occurred among 35,676 births including Live Birth, still births, intra uterine deaths and bortions. Our hospital is a major tertiary referral centre for four surrounding districts which caters to more than $60 \%$ of unbooked high risk cases. In this study maternal mortality with regard to age, marital status, age at marriage, obstetric score, booked vs unbooked, rural vs urban, socio economic status, educational status, time interval since admission, mode of delivery and causes of death were critically analyzed.

Majority of maternal deaths have occurred in the age group of 21-25 years and this correlates with Surendranath Panda et al (2000) ${ }^{3}$ and Nikhil Purandare et al (2007). ${ }^{4}$ Most of the maternal deaths were in unbooked cases and was consistent with Verma Ashok et al (2008) ${ }^{5}$ and Abha Aggarwal et al (2007). ${ }^{6}$ Regular ANCs reduce MMR.
In the present study majority of maternal deaths occurred in rural populations and this correlated with the study Verma Ashok et al (2008) ${ }^{5}$ and Jadhav AJ et al (2007). ${ }^{7}$ The rural populations are at greater risk due to poor transport facilities to reach the referral central in time.

In the present study majority of maternal deaths occurred in low and middle socio economic status people and this correlated with Verma Ashok et al (2008). ${ }^{5}$ In our present study, educational status of women is comparatively better when compared to other studies. Majority of deaths have occurred in women who are illiterate and who had upto secondary education in contrast to Surendranath Panda et al studies where majority of maternal deaths have occurred in women who are illiterate and who had upto primary education. ${ }^{3}$ Women with education are more likely to marry later, delay child bearing, use family planning methods, seek antenatal care and make use of obstetric services available at their locality.

During the study period, majority of maternal deaths had occurred in women who had married at teen ages. This finding is consistent with the result reported by Abha Aggarwal et al (2007). ${ }^{6}$ Many of 
these girls have not matured properly and have smaller pelvices. Therefore the incidence of malnutrition, anaemia, pre-eclampsia, fetal mal presentations, cephalopelvic disproportion, prolonged and dystocic labours ending up in obstructed labours is higher.

In our study, majority of the deaths have occurred within 24 hours of admission which correlates with the result obtained from Surendranath Panda et al (2000). ${ }^{3}$ This is due to delayed referral resulting in late intervention and lack of qualified medical attention. This also highlights the importance of adequate and quick transport facilities.

In our study, majority of maternal deaths have occurred in women who had vaginal delivery, which correlates with the results obtained from the study of Nikhil Purandare et al (2007). ${ }^{4}$ This is because many deliveries were occurred at home and peripheral centers and referred to hospital at later stages.

The result of the present study correlates with Surendranath Panda et al (2000) and Verma Ashok et al (2008) with the direct obstetric causes contributing to the majority of maternal deaths., ${ }^{3,5}$ Our present study also correlates with WHO study $^{8}$ and $\mathrm{SRS}^{2}$ in India. Because of lack of awareness, irregular ANCs and other social factors prevent women from approaching hospital. Haemorrhage and hypertensive disorders of pregnancy are the major direct causes contributing equally to the causation of maternal mortality in our study, in contrast to Studies by Nikhil Purandare et $\mathrm{al}^{4}$, Surendranath Panda et $\mathrm{al}^{3}, \mathrm{SRS}^{2}$ and WHO studies $^{8}$ where haemorrhage is the leading direct cause of maternal mortality. Most deaths in our study occurred inspite of availability of blood bank facility and availability of specialist doctors within the hospital. Although obstetric haemorrhage is vigorously tackled, the prevalence of nutritional anaemia and poor general condition failed to prevent the maternal tragedy.

In our study, anaemia is the leading indirect cause of maternal mortality which correlates with the results from
Surendranath Panda et al (2000) ${ }^{3}$ and Verma Ashok et al (2008). ${ }^{5}$ Pre-existing anaemia worsens as pregnancy advances leading to congestive heart failure and death. It also impedes the mother's ability to resist infection or cope with haemorrhage and increases the likelihood of her dying in childbirth by a factor of four.

\section{CONCLUSIONS}

Reviewing the maternal deaths that occurred in our hospital, there is an urgent need to address the issue of obstetric haemorrhages and early intervention in PIH. Much needs to be done for maternal health care in rural areas as most of the deaths reported from urban institutions are referrals from peripheral centers. Rapid transport facilities should be made available to all remote rural areas with easy accessibility. It is necessary even in urban areas to channel the working of emergency obstetric care. Facilities in the urban hospitals are grossly inadequate with the shortage of anesthetists, pathologists and blood banks. This prevents early intervention and adequate emergency obstetric care. As well as cooperation with other departments is essential in cases of medical disorders complicating during pregnancy. The essential obstetric care for all and early detection of complications and management of emergency obstetric care services need to be seriously looked into. Post mortem examination should be conducted in all maternal deaths where the cause of death is in doubt. The public should be convinced to realize the importance of such procedure. Traditional birth attendants should be given adequate training to recognize abnormalities of pregnancy and labour since a large number of deliveries are still conducted at home in rural areas. Most maternal deaths are preventable by health education of masses, adequate health care in the community and transport facilities.

Funding: No funding sources

Competing interests: There are no competing interests to declare

Ethical approval: The study was approved by the institutional ethical committee 


\section{REFERENCES}

1. Costello A, Ostin D, Manandhar D. Reducing maternal and neonatal mortality in the poorest communities. BMJ 2004;329:1166-8.

2. Registrar General of India. Maternal mortality in India: 1997-2003: trends, causes and risk factors; summary. New Delhi: Office of the Registrar General of India; 2006.

3. Panda S, Das BB, Patnaik A. An investigation into maternal mortality. Paper presented at the 44th All India Congress of Obstetricians and Gynaecologists, Ahmedabad; 28-31 December 2000.

4. Purandare N, Chandock AS, Upadhya S, Sanjanwala SM, Saraogi RM. Maternal mortality at a referral centre: a five year study. J Obstet Gynecol India 2007;57:24850 .

5. Verma A, Minhas S, Sood A. A study on maternal mortality. J Obstet Gynecol India 2008;58:226-9.

6. Aggarwal A, Pandey A, Bhattacharya BN. Risk Factors for maternal mortality in Delhi slums: a community based case-control study. Indian J Med Sci 2007;61:517-26.

7. Jadhav AJ, Rote PG. Maternal mortalitychanging trends. J Obstet Gynaecol India 2007;57:398-400.

8. World Health Organization (WHO), authors The World Health Report 2005: Make Every Mother and Child Count. Geneva, Switzerland: WHO; 2005. Available at http://www.who.int/whr/2005/whr2005_en.p df. Accessed 9 September 2012. 